\title{
Determinants of Ectopic Pregnancy among Pregnant Women Who Were Managed in Nekemte Referral Hospital, Oromia Region, Ethiopia
}

\author{
Yeshiwork Kebede ${ }^{1}$, Gizew Dessie ${ }^{2,3}$ \\ Integrated Emergency Surgery and Obstetrics, Jimma University, Jimma, Ethiopia \\ ${ }^{2}$ Department of Pharmacy, School of Pharmacy, University of Gondar, Gondar, Ethiopia \\ ${ }^{3}$ Human Resource for Health Management, Institute of public health, University of Gondar, Gondar, Ethiopia
}

*Corresponding author: Gizew Dessie, B.Pharm, Department of Pharmacy, School of Pharmacy; MPH in Human Resource for Health Management, Institute of public health, University of Gondar, Gondar, Ethiopia; E-mail: gizew.dessie@gmail.com

\begin{abstract}
Ectopic pregnancy (EP) is a pregnancy in which the implantation of the embryo occurs outside the uterine cavity. It is the leading cause of maternal death during the first trimester of pregnancy. A better understanding of its risk can help prevent its incidence. This case-control study was carried out to evaluate the risk factors for ectopic pregnancy in Nekemte Referral Hospital, Ethiopia. The objective of this study was to identify the determinants of ectopic pregnancy among pregnant women who were managed in Nekemte Referral Hospital, 2015. The design was hospital based unmatched case control study. Detailed reviews of patient record were made by using structured check list all required information have been collected 99 cases with ectopic pregnancy were taken as a whole whereas 200 controls have been selected with simple random sampling method. Data was entered and cleaned using Epi Info version 7 then exported to SPSS version 20 for analysis. Bi-variable analysis was executed then all explanatory variables with p-value of $<0.25$ were entered into multivariable logistic regression. Determinant factors have been identified based on p-value of 0.05 and AOR with 95\% CI. From January 2010 to December 2013, there were 99 cases of ectopic pregnancy in Nekemte Referral Hospital. The average $( \pm \mathrm{SD})$ of patient's age was $27( \pm 5)$ years. The risk factors identified were marital status and history of contraception use. Accordingly, women with single marital status were 10.81 times (95\% CI AOR $(3.601,32.465))$ more likely to develop ectopic pregnancy than married ones. Those who used contraception were 2.27 times $(95 \%$ CI, AOR $(0.214,24.02))$ more likely to develop ectopic pregnancy than who did not use contraception.
\end{abstract}

Keywords: Ectopic pregnancy; Determinants; Oromia; Ethiopia

\section{Introduction}

Ectopic pregnancy is derived from the Greek word "ektopos" means out of place and it refers to implantation of a fertilized egg in a location outside of the uterine cavity ${ }^{[1,2]}$. It occurs in approximately $1-2 \%$ of pregnancies and it is the most important cause of maternal morbidity and mortality in the first trimester $^{[3,4]}$. The etiology of ectopic pregnancy is not well understood. However, multiple risk factors have been associated with ectopic pregnancy, although some patients may not have any risk factor.

Theoretically, any condition that prevents or retards the normal transport of the fertilized ovum to the uterus could predispose women to ectopic gestation ${ }^{[5-7]}$. Several risk factors for ectopic pregnancy have been identified, including a history of pelvic inflammatory disease (PID), smoking at the time of conception, previous ectopic pregnancy, previous pelvic surgery, induction of ovulation, and intrauterine device usage. An understanding of the risk factors for ectopic pregnancy assists more rapid diagnosis and could result in a reduction in the need for surgery, and an improvement in preventive strategies against ectopic pregnancy ${ }^{[8]}$.

A "classic" presentation of ectopic pregnancy is characterized by the triad of delayed menstruation, pain, and vaginal bleeding or spotting ${ }^{[9]}$. Classically, the diagnosis is based on a

Received date: April 9, 2018

Accepted date: October 1, 2018

Published date: October 4, 2018

Citation: Gizew, D., et al. Determinants of Ectopic Pregnancy Among Pregnant Women Who Were Managed in Nekemte Referral Hospital, Oromia Region, Ethiopia. (2018) J Gynecol Neonatal Biol 4(1): 27-33.

Copyright: (C) 2018 Gizew, D. This is an Open access article distributed under the terms of Creative Commons Attribution 4.0 International License. 
Citation: Gizew, D., et al. Determinants of Ectopic Pregnancy Among Pregnant Women Who Were Managed in Nekemte Referral Hospital, Oromia Region, Ethiopia. (2018) J Gynecol Neonatal Biol 4(1): 27-33.

history of pelvic pain associated with amenorrhea, a positive pregnancy test with or without slight vaginal bleeding ${ }^{[10]}$.

The treatment of ectopic pregnancy is influenced by the clinical state of the patient, site of the ectopic gestation, the reproductive wish of the patient as well as availability of facilities and technological expertise. However, surgical intervention remains as the norm of treatment ${ }^{[11]}$.

\section{Statement of the problem}

Ectopic pregnancy is the leading cause of maternal morbidity and mortality worldwide ${ }^{[12]}$.

In the western world, the incidence of EP is approximately $1-2 \%$ in the general population but as high as $20 \%$, in patients who have undergone tubal surgery. Risk factors for EP after natural conception (e.g., tubal surgery, previous EP, pelvic inflammatory disease, and infertility) have been well described. Ectopic pregnancy remains a leading cause of maternal mortality and morbidity in the first trimester of pregnancy in developing countries $^{[13]}$.

Ethiopia is one of the six countries which have contributed to more than $50 \%$ of all maternal deaths across the world $^{[14,15]}$. Among the causes of maternal mortality, ectopic pregnancy is the leading in the first trimester of pregnancy. Approximately $1-2 \%$ of all naturally conceived pregnancies end up with ectopic pregnancy ${ }^{[16,17]}$. In the past decades, the occurrence of ectopic pregnancy has been raised in many countries though the condition varies from country to country depending on the risk factors predominant in the geographical region ${ }^{[5]}$.

The identified risk factors for ectopic pregnancy include prior history of ectopic pregnancy, history of appendectomy, previous pelvic surgery, history of pelvic infection, early age, prior spontaneous and medical abortion, history of contraceptive use including emergency pills, cigarette smoking in dose dependent manner, history of having multiple sexual practices, history of infertility, usage of artificial reproductive technology, presence of a hydrosolpinx or fibroid ${ }^{[18,19]}$.

Worldwide, different risk factors are identified but women in Ethiopia, Nekemete have different characteristics (cultural, religious, socio-demographic characteristics, sexual behavior and beliefs, contraception usage and preference). Therefore, risk factors for ectopic pregnancy may differ from place to place. So, this case-control study conducted to identify the risk factors in the study area.

\section{Methods}

\section{Study design and Period}

A hospital based unmatched case control study was employed. The study was conducted on October 1-30, 2015 in NRH.

Source population and Study population: Source population of this study was record of all pregnant women who had visited NRH in Gynecological OPD, ANC and maternity ward from $1 / 07 / 2014$ to $1 / 07 / 2015$. The study population of this study was record of pregnant women who were diagnosed by ultrasound to have intra-uterine pregnancy or ectopic pregnancy in Gynecological OPD, ANC clinic, maternity ward and operation room.

\section{Eligibility criteria}

Inclusion criteria: Record of pregnant women who were diagnosed to have intra-uterine pregnancy or ectopic pregnancy at any gestational age and both singleton and multiple type of pregnancy in gynecological OPD, ANC clinic, maternity ward and operation room.

Exclusion criteria: Record of pregnant women with incomplete data (gravidity, abortion history, ectopic history, history of STI, history of contraceptive use, obstetric and gynecologic surgery, etc) from patient medical record folder.

\section{Sample size and sampling technique}

Sample size was calculated using Epi Info version 7 for unmatched case control study design (Table 1) based on the assumption that PID is significant risk factor for ectopic pregnancy. From previous case control study with $3.0 \%$ of controls and $13.4 \%$ of cases were having prior history of PID and the level of significance $\alpha=0.05$, the power of the test $(1-\beta)=80 \%$, the control to case ratio(r) $=2$, the proportion of exposure among controls $(\mathrm{p} 1)=3 \%$ with the proportion of exposure among cases $(\mathrm{p} 2)=13.4 \%$ and $\mathrm{AOR}=5$. The final sample size calculated by using the above assumption gives 88 cases and 176 controls with a total of 264 study subjects. However, since there are 99 actual cases in the study period, it was found preferable to take all the total cases in 1:2 ratios to have a total of 299 study subjects.

Table 1: Epi Info sample size calculation ${ }^{[20]}$

\begin{tabular}{|l|c|c|c|}
\hline & Kelsey & Fleiss & Fleiss with CC \\
\hline Sample Size - Exposed & 66 & 75 & 88 \\
\hline Sample Size-Non exposed & 132 & 149 & 176 \\
\hline Total sample size: & 198 & 224 & 264 \\
\hline
\end{tabular}

\section{Sampling procedure}

Simple random sampling technique was used to select study participants with intra uterine pregnancy (controls) while for cases all subjects were included as their number was only 99 from $1 / 07 / 2014$ to $1 / 07 / 2015$.

\section{Variables of the study}

Dependent variable: State of pregnancy (Ectopic pregnancy or Normal pregnancy)

Independent variables: Socio-demographic variables (Age, Marital status, Religion, Ethnicity, Address, Habits (Alcohol drinking, cigarette smoking))

Obstetric and Gynecological variables (Gravidity, Abortion history, Ectopic history, History of STI, History of contraceptive use, Obstetric and gynecologic surgery)

Co-morbid diseases

\section{Data collection procedure}

The available information on the patient records had been first observed and appropriate data extraction format was prepared in English. Then the data were collected by year one 4 IESO students using the prepared data collection format on the already existing records after half a day theoretical and half a day practical training was given. One data clerk also supported them by identifying the charts. One supervisor and principal investigator were controlling every activity during data collection. 
Charts were retrieved using the patient registration number which was found in the registration of Operation Theater, ANC and GYN OPD and maternity sections of the hospital.

\section{Data quality control}

Quality of data were maintained by recruiting data collectors who are IEOS year one and supervisor IESO year three. The data collectors and supervisor were given intensive training for one day before the data collection on the objective of the study and how to retrieve data for this study purpose using the data extraction format. They briefed on the definition of variables on the questionnaires and registration charts. The data extraction tool was pre-tested for consistency of understanding the review tools and completeness of data items on 10 charts at the same facility as it was a secondary data and the necessary amendment were made on the final data extraction format. The retrieval process was closely monitored by the principal investigator throughout the data collection period. Completed questionnaires were checked regularly for completeness of information and any gaps identified were immediately communicated to the data collectors.

\section{Data processing and analysis}

Data were first checked manually for completeness and consistency by supervisor and principal investigator during data collection and rechecked again before data entry. Data was entered and cleaned using Epi Info version 7 then exported to SPSS version 20 for analysis and interpretation. Descriptive analysis was conducted to summarize the data. Bi-variable analysis was executed to see the association between independent and outcome variables. All explanatory variables associated with outcome variables with $p<0.25$ were entered into Multivariable logistic regression analysis. Back ward conditional method was used and Variables with a p-value $<0.05$ in multi-variable analysis were considered as significant risk factor for ectopic pregnancy.

\section{Ethical Consideration}

Ethical clearance was obtained from the Institutional review board of Jimma University College of health sciences. Permission letter was obtained from Nekemte Referral Hospital's management, and oral permission also obtained from focal person in the respected wards to use the secondary data for the purpose of this study. The name or any other identifying information was not recorded on the questionnaire and all information taken from the chart was kept strictly for confidential and in a safe place. The information retrieved was used only for the study purpose.

\section{Limitations of study}

Since the study is based on secondary data, this study faced limitation of detailed information like; details of socio demographic variables. Since the study is institutional based, findings couldn't generalize the general population unlike prospective population based study.

\section{Results}

\section{Socio-Demographic, clinical characteristic of participants}

From October 1-30, 2015, there were 99 cases of ectopic pregnancy in Nekemet hospital. The average age was $27 \pm 5$ years. Majority of participants were married 91.31\% (273 of 299) and almost half of them 50.5\% (151 of 299) came from Nekemte town.

Only 5.0\% (15 of 299) and 18.39\% (55 of 299) of study participant had previous history of ectopic pregnancy and abortion respectively while $23.41 \%$ ( 70 of 299 ) had previous history of surgery with $48.5 \%$ (34 of 70 ) cases of C/s. one third $29.10 \%$ ( 87 of 299) of participants had history of STI with $57.4 \%$ (50 of 87) of PID and $42.5 \%$ (37 of 87) of vaginal discharge.

Among Contraceptive users 207 of 299 (69\%), Depo-Provera was highest one 62.3\% (129 of 207). one in three (32.78\%) , had four or more history of gravida and about $21.4 \%$ (64 of 299) had co-morbid disease including hypertension $64 \%$ (41 of 64), DM 17.2\%(11 of 64), HIV 12.5\% (8 of 64) and asthma6.3\% (4 of 64) (Table 2).

Table 2: Distribution of Ectopic Pregnancy with socio demographic and clinical characteristics, Nekemte Referral Hospital, 2015.

\begin{tabular}{|c|c|c|c|c|c|}
\hline \multirow{2}{*}{\multicolumn{2}{|c|}{ Variables }} & \multicolumn{2}{|c|}{ State of pregnancy } & \multirow{3}{*}{$\begin{array}{c}\text { Frequency } \\
30\end{array}$} & \multirow{3}{*}{$\begin{array}{c}\text { Percentage (\%) } \\
10.03\end{array}$} \\
\hline & & \multirow{2}{*}{$\begin{array}{c}\text { Ectopic }(\text { cases }=99) \\
14\end{array}$} & \multirow{2}{*}{$\begin{array}{c}\text { Normal }(\text { controls }=\mathbf{2 0 0}) \\
16\end{array}$} & & \\
\hline \multirow{3}{*}{ Age } & $<=20$ & & & & \\
\hline & $21-30$ & 66 & 136 & 202 & 67.56 \\
\hline & $>=31$ & 19 & 48 & 67 & 22.41 \\
\hline \multirow{4}{*}{ Marital Status } & Single & 16 & 2 & 18 & 6.02 \\
\hline & Married & 79 & 194 & 273 & 91.31 \\
\hline & Divorced & 2 & 3 & 5 & 1.67 \\
\hline & Widowed & 2 & 1 & 3 & 1.00 \\
\hline \multirow{2}{*}{ Address } & Nekemet & 50 & 101 & 151 & 50.50 \\
\hline & Out of Nekemet & 49 & 99 & 148 & 49.50 \\
\hline
\end{tabular}


Citation: Gizew, D., et al. Determinants of Ectopic Pregnancy Among Pregnant Women Who Were Managed in Nekemte Referral Hospital, Oromia Region, Ethiopia. (2018) J Gynecol Neonatal Biol 4(1): 27-33.

\begin{tabular}{|c|c|c|c|c|c|}
\hline \multirow{4}{*}{ Habits } & Alcohol drinking & 30 & 60 & 90 & 30.10 \\
\hline & Non alcohol drinking & 69 & 140 & 209 & 69.90 \\
\hline & Non cigarette smoking & 99 & 200 & 299 & 100 \\
\hline & Cigarette smoking & 0 & 0 & 0 & 0 \\
\hline \multirow{2}{*}{ Hx of Abortion } & Yes & 21 & 34 & 55 & 18.39 \\
\hline & No & 78 & 166 & 244 & 81.61 \\
\hline \multirow{3}{*}{ No. of Abortion } & $\mathbf{0}$ & 78 & 166 & 244 & 81.61 \\
\hline & 1 & 17 & 26 & 43 & 14.38 \\
\hline & $>=2$ & 4 & 8 & 12 & 4.01 \\
\hline \multirow{2}{*}{$\begin{array}{l}\text { Hx of Ectopic } \\
\text { pregnancy }\end{array}$} & Yes & 7 & 8 & 15 & 5.01 \\
\hline & No & 92 & 192 & 284 & 94.98 \\
\hline \multirow{2}{*}{ Hx of surgery } & Yes & 21 & 49 & 70 & 23.41 \\
\hline & No & 78 & 151 & 229 & 76.59 \\
\hline \multirow{3}{*}{ Type of surgery } & $\mathrm{C} / \mathrm{s}$ & 9 & 25 & 34 & 11.37 \\
\hline & Others & 12 & 24 & 36 & 12.04 \\
\hline & No Hx & 78 & 151 & 229 & 76.59 \\
\hline \multirow{2}{*}{ Hx of STI } & Yes & 25 & 62 & 87 & 29.10 \\
\hline & No & 74 & 138 & 212 & 70.90 \\
\hline \multirow{3}{*}{ STI syndrome } & PID & 18 & 32 & 50 & 16.72 \\
\hline & Vx discharge & 7 & 30 & 37 & 12.37 \\
\hline & No Hx & 74 & 138 & 212 & 70.90 \\
\hline \multirow{2}{*}{$\begin{array}{l}\text { Hxof } \\
\text { Contraceptive use }\end{array}$} & Yes & 60 & 147 & 207 & 69.23 \\
\hline & No & 39 & 53 & 92 & 30.77 \\
\hline \multirow{5}{*}{$\begin{array}{l}\text { Type of } \\
\text { Contraceptive use }\end{array}$} & IUCD & 11 & 13 & 24 & 8.03 \\
\hline & Depo & 33 & 96 & 129 & 43.14 \\
\hline & Implanon & 4 & 17 & 21 & 7.02 \\
\hline & OCP & 12 & 21 & 33 & 11.04 \\
\hline & No & 39 & 53 & 92 & 30.77 \\
\hline \multirow{4}{*}{ Gravidity } & I & 29 & 48 & 77 & 25.75 \\
\hline & II & 22 & 46 & 68 & 22.74 \\
\hline & III & 18 & 38 & 56 & 18.73 \\
\hline & $>/=\mathbf{I v}$ & 30 & 68 & 98 & 32.78 \\
\hline \multirow{2}{*}{ Co-morbid Disease } & Yes & 17 & 47 & 64 & 21.40 \\
\hline & No & 82 & 153 & 235 & 78.60 \\
\hline \multirow{5}{*}{$\begin{array}{l}\text { Type of Co- } \\
\text { morbidity }\end{array}$} & No Hx & 82 & 153 & 235 & 78.60 \\
\hline & Hypertension & 6 & 35 & 41 & 13.71 \\
\hline & Diabetic mellitus & 6 & 5 & 11 & 3.68 \\
\hline & HIV & 5 & 3 & 8 & 2.68 \\
\hline & Asthma & 0 & 4 & 4 & 1.34 \\
\hline \multirow{2}{*}{ Hgb level } & $<11$ gm/dl & 51 & 23 & 74 & 24.75 \\
\hline & $>=11 \mathrm{gm} / \mathrm{dl}$ & 48 & 177 & 225 & 75.25 \\
\hline
\end{tabular}

Others; types of surgery other than CS

\section{Risk factor for Ectopic pregnancy}

Findings from bi-variable logistic regression analysis showed that age, marital status, history of contraceptive user, type of contraceptive used and prior history of STI syndrome had association with ectopic pregnancy with p-value of less than 0.25 . However, in multi-variable regression analysis, only marital status and history of contraceptive use remained statistically significant risk factor for ectopic pregnancy.

Accordingly, women with single marital status were 10.81 (95\% CI A0R (3.601,32.465), p - value 0.001) times higher risk to developed ectopic pregnancy than married ones and history of contraceptive use was 2.27 AOR $(0.214,24.02)$ times more likely to develop ectopic pregnancy than those who had no history of contraceptive use (Table 3 ). 
Table 3: Sociodemographic and clinical characteristics of women with state of pregnancy (ectopic vs. intrauterine pregnancy).

\begin{tabular}{|c|c|c|c|c|c|}
\hline \multirow{2}{*}{\multicolumn{2}{|c|}{ Variables }} & \multicolumn{2}{|c|}{ State of pregnancy } & \multicolumn{2}{|c|}{ OR (95\%) } \\
\hline & & \multirow{2}{*}{$\begin{array}{c}\text { Ectopic } \\
14\end{array}$} & \multirow{2}{*}{$\begin{array}{c}\text { Normal } \\
16\end{array}$} & \multirow{2}{*}{$\begin{array}{c}\text { COR } \\
2.21(0.91,5.40)\end{array}$} & \multirow[t]{2}{*}{ AOR } \\
\hline \multirow{3}{*}{ Age } & $<=20$ & & & & \\
\hline & $21-$ & 66 & 136 & $1.23(0.67,2.25)$ & \\
\hline & $>=31$ & 19 & 48 & 1 & \\
\hline \multirow{2}{*}{ Marital status } & Single & 20 & 6 & $8.19(3.17,21.15)$ & $10.81(3.60,32.47)$ \\
\hline & Married & 79 & 194 & 1 & Reference \\
\hline \multirow{2}{*}{ Address } & Nekemet & 50 & 101 & $1.00(0.62,1.62)$ & \\
\hline & Out of Nekemet & 49 & 99 & 1 & \\
\hline \multirow{2}{*}{ Abortion $\mathbf{H x}$} & Yes & 21 & 34 & $1.31(0.72,2.41)$ & \\
\hline & No & 78 & 166 & 1 & \\
\hline \multirow{3}{*}{ Hxof \# Abortion } & $\mathbf{0}$ & 78 & 166 & 1 & \\
\hline & 1 & 17 & 26 & $1.39(0.71,2.41)$ & \\
\hline & $>=2$ & 4 & 8 & $1.06(0.31,3.64)$ & \\
\hline \multirow{2}{*}{ Ectopic Hx } & Yes & 7 & 8 & $1.83(0.64,5.19)$ & \\
\hline & No & 92 & 192 & 1 & \\
\hline \multirow{2}{*}{ Hx of surgery } & Yes & 21 & 49 & $0.83(0.47,1.48)$ & \\
\hline & No & 78 & 151 & 1 & \\
\hline \multirow{3}{*}{ Type of surgery } & No & 78 & 151 & 1 & \\
\hline & $\mathrm{C} / \mathrm{s}$ & 9 & 25 & $0.70(0.31,1.57)$ & \\
\hline & Others & 12 & 24 & $0.97(0.46,2.04)$ & \\
\hline \multirow{2}{*}{ Hx of STI } & Yes & 25 & 62 & $0.75(0.44,1.30)$ & \\
\hline & No & 74 & 138 & 1 & \\
\hline \multirow{3}{*}{ STI syndrome } & No & 74 & 138 & 1 & \\
\hline & PID & 18 & 32 & $1.05(0.55,1.99)$ & \\
\hline & Vx discharge & 7 & 30 & $0.44(0.18,1.04)$ & \\
\hline \multirow{2}{*}{ Hxof Contraceptive use } & Yes & 60 & 147 & $0.56(0.33,0.93)$ & $2.27(0.21,24.02)$ \\
\hline & No & 39 & 53 & 1 & \\
\hline \multirow{5}{*}{ Type of Contraceptive used } & No & 39 & 53 & 1 & \\
\hline & IUCD & 11 & 13 & $1.15(0.466,2.837)$ & $1.32(0.53-3.34)$ \\
\hline & Depo & 33 & 96 & $0.47(0.264,0.828)$ & $0.56(0.31,1.0)$ \\
\hline & Implanon & 4 & 17 & $0.32(0.100,1.025)$ & $0.26(0.73,0.9)$ \\
\hline & OCP & 12 & 21 & $0.78(0.342,1.765)$ & $0.41(1.44,1.16)$ \\
\hline \multirow{4}{*}{ Gravidity } & One & 29 & 48 & $1.37(0.729,2.572)$ & \\
\hline & Two & 22 & 46 & $1.08(0.557,2.109)$ & \\
\hline & Three & 18 & 38 & $1.07(0.530,2.176)$ & \\
\hline & Four and more & 30 & 68 & 1 & \\
\hline \multirow{2}{*}{ Co-morbid Diseases } & Yes & 17 & 47 & $0.68(0.364,1.250)$ & $0.74(0.39,1.42)$ \\
\hline & No & 82 & 153 & 1 & \\
\hline
\end{tabular}

\section{Discussion}

This case control study tried to identify the determinants of EP in Nekemte Referral Hospital. In this study the mean age was $27 \pm 5$ years, similar studies done in Lagos, Nigeria and Niger Delta showed the mean age was $27.8 \pm 6.21$ years and 26.8 years respectively ${ }^{[12,17]}$.

Majority of participants in this study were married $91.3 \%$ (273 of 299) which is the same as that of the study done in Aminu Kano Hospital Nigeria ${ }^{[2]}$.

In this case control study many variables that have been well studied and identified as a risk factor do not appeared to show association with ectopic pregnancy and the variable that were identified as risk factors for ectopic pregnancy were marital status and history of contraception use ${ }^{[18-21]}$. This may be real differences in the risk of developing ectopic pregnancy in study participants. 
Citation: Gizew, D., et al. Determinants of Ectopic Pregnancy Among Pregnant Women Who Were Managed in Nekemte Referral Hospital, Oromia Region, Ethiopia. (2018) J Gynecol Neonatal Biol 4(1): 27-33.

Worldwide, different risk factors are identified but women in Ethiopia, Nekemete have different characteristics (cultural, religious, socio-demographic characteristics, sexual behavior and beliefs, contraception usage and preference). Therefore, risk factors for ectopic pregnancy may differ from place to place.

Thus, women with single marital status were 10.81 (95\% CI A0R $(3.60,32.47))$ times higher risk to developed ectopic pregnancy than married ones. This may be because single women are prone for having multiple sexual partners ${ }^{[23,24]}$, PID, STI and likely to use contraceptive like emergency pills that are likely to increase the risk of ectopic pregnancy than those married women.

To my knowledge this is the first study that tries to identify risk factor to ectopic pregnancy in the study area. Like other case control studies it has certain limitation ${ }^{[25]}$. The first was ascertained based on the written records in clients chart. The other was difficulty of findings similar research to compare the main findings of this thesis. The last but not the least was as it is based on chart review, it was impossible to get complete record of other variables like educational status, alcohol use, cigarette smoking and so on which could have impact on the occurrence of ectopic pregnancy.

\section{Conclusion}

Although several risk factors for ectopic pregnancy are known, the only factors associated were marital status and history of contraception use. Accordingly, women with single marital status were 10.81 times $(95 \%$ CI AOR $(3.601,32.465)$ ) more likely to develop ectopic pregnancy than married ones. Those who used contraceptive were 2.27 times $(95 \%$ CI, AOR $(0.214$, 24.02)) more likely to develop ectopic pregnancy.

\section{Recommendation}

Though it is not identified in this study, there are known risk factors for ectopic pregnancy, thus large scale study shall be conducted to identify possible determinates of ectopic pregnancy. Tracing and integrated management of sexually transmitted infection is very important so as to reduce the incidence of pelvic infection and EP. The clinicians need to record all the findings on medical charts of the patients and Patient's medical records should be kept appropriately.

\section{Acknowledgements}

It is a pleasure to me to forward my heartfelt gratitude to the advisors Demisew Amenu (Gynecologist \& obstetrician) $\&$ Elias Ali (MD, MPH) for their unreserved and constructive comments and follow up right from selection of title to completion of thesis. We would also like to thank Jimma University for giving me this opportunity. We would like also to thank Nekemte referral hospital. Last but not least we would like to acknowledge UNFPA for financial support.

\section{References}

1. Goyaux, N., Leke, R., Keita, N., et al. Ectopic pregnancy in african developing countries. (2003) Acta Obs Gynecol Scand 82(82): 305-312.

Pubmed | Crossref | Others

2. Nathalia, T.M. Clinical presentation and factors associated with long hospital stay among the suspects of ectopic pregnancy at bugando medical centre mwanza tanzania. (2013). Pubmed | Crossref | Others

3. Yeasmin, M.S., Uddin, J.M., Hasan, E. A clinical study of ectopic pregnancies in a tertiary care hospital of chittagong, bangladesh. (2014) Bangladesh Journals Online 13(3): 2-5. Pubmed | Crossref | Others

4. Watts, J., Blackwell, A., Thomson, A., et al. Management of ectopic pregnancy management of ectopic pregnancy guideline. 1-13.

Pubmed | Crossref $\mid$ Others

5. Sabira, S., Asif, M.H., Akhtar, N. Incidence rate and prevalence of major risk in the pakistani population : mini-review factors for ectopic pregnancy. (2015) Asian Pacific J Tropical Dis 5(3): 246-250.

Pubmed | Crossref | Others

6. Kishore, N., Prabhakar, S., Pooja, P. S., et al. Ectopic pregnancy after sequential embryo transfer: review of 22 cases. (2015) Int J Med Res 4(3): 659-661. Pubmed | Crossref | Others

7. Dabota, B. Y. Management and outcome of ectopic pregnancy in developing countries. (2011) Intech Open 109-136 Pubmed | Crossref | Others

8. Karaer, A., Avsar , F., Batioglu, S. Risk factors for ectopic pregnancy: a case-control study. (2006) J Res Med Sci 46(6): 521-527.

Pubmed | Crossref | Others

9. Cunningham, G. F., Kenneth, J. Leveno williams obstetrics, $24^{\text {th }}$ edition. (2014) 379.

Pubmed | Crossref $\mid$ Others

10. Nama, V., Manyonda, I. Tubal ectopic pregnancy : diagnosis and management. (2009) Arch Gynecol Obs 443-453. Pubmed $\mid$ Crossref $\mid$ Others

11. Olaifa, K., Aquaisua, A. N., Ikpeme, E., et al. Ectopic pregnancy : a nigerian urban experience. (2012) J Obst Gyne 55(5): 309-314.

Pubmed |Crossref $\mid$ Others

12. Anorlu, R. I., Oluwole, A.,Olalekan, O. A., et al. Risk factors for ectopic pregnancy in Logas Nigeria. (2005) Acta Obstet Gynecol Scand 84(6):184-188.

Pubmed | Crossref | Others

13. Strandell, A., Thorburn, T., Hamberger, L.. Risk factors for ectopic pregnancy in assisted reproduction. (1999) Fertil Steril 71(2): 282-286.

Pubmed $\mid$ Crossref $\mid$ Others

14. Ashebir, G. Maternal mortality studies in ethiopia- magnitude, causes and trends. (2009) Euthopian Med J 47(2): 95-108 .

Pubmed | Crossref $\mid$ Others

15. Abouzahr, C. Global burden of maternal death and disability. (2003) Br Med Bull 67(1): 1-11

Pubmed |Crossref $\mid$ Others

16. Thonneau, P., Hijazi, Y., Goyaux, N., et al. Ectopic pregnancy in conakry, Guinea. (2002) Bull World Health Org 
80(5):365-370.

Pubmed | Crossref | Others

17. Igberase, G.O., Ebeigbe, P.N., Igbekoyi, O.F., et al. Ectiopic Pregnancy: an 11-year review in a tertiary centre in the niger delta. (2005) Tropical Doctor 35(3): 175-177. Pubmed | Crossref | Others

18. Bouyer, J., Coste, J., Shojaei, T, et al. Risk factors for ectopic pregnancy : a comprehensive analysis based on a large case-control , population-based study in france. (2003) J Res Med Sci 157(3): 185-194.

Pubmed | Crossref | Others

19. Li, C., Meng, C, Zhao, W., et al. European journal of obstetrics \& gynecology and reproductive biology risk factors for ectopic pregnancy in women with planned pregnancy : a case - control study. (2014) Eur J Obstet Gynecol 181: 176-82.

Pubmed $\mid$ Crossref $\mid$ Others

20. Wacholder, S., Silverman, D.T., McLaughlin, J.K., et al. Selection of controls in case-control studies: III. Design options. (1992) Am J epidemiology 135(9):1042-1050.

Pubmed | Crossref | Others

21. Rabiu,A., Galadanci, H.S. Risk factors and outcomes of ectopic pregnancies at aminu kano teaching hospital, kano, nigeria. (2013) Tropical J Obest and Gynec 30(2): 105-112. Pubmed | Crossref $\mid$ Others

22. Michalas, S., Minaretzis, D.,Tsionou, C., et al. Pelvic surgery, reproductive factors and risk of ectopic pregnancy : a case controlled study. (1992) Int J Gyne and Obest 38(2): 101-105.

Pubmed | Crossref $\mid$ Others

23. Bouyer, J., Rachou, E., Germain, E., et al. Risk factors for extrauterine pregnancy in women using an intrauterine device. (2000)Fertil Steril 74(5): 899-908.

Pubmed | Crossref | Others

24. Li, C., Zhao, W, Zhu, Q, Cao, S., et al. Risk factors for ectopic pregnancy : a multi- center case-control study. (2015) BMC Preg Child Birth 15: 187.

Pubmed | Crossref | Others

25. Finne, G.K., Paul, M. Gargiulloa, D.J. Kendrick a prospective study, multiple induced abortions as risk factor of ectopic pregnancy: A Prospective study. (1997) Acta Obstet Gynecol Scand 76(7): 691-696.

Pubmed | Crossref | Others
Submit your manuscript to Ommega Publishers and we will help you at every step:

- We accept pre-submission inquiries

- Our selector tool helps you to find the most relevant journal

- We provide round the clock customer support

- Convenient online submission

- Thorough peer review

- Inclusion in all major indexing services

- Maximum visibility for your research

Submit your manuscript at

OMmEga Publishers 